\title{
True Decommissioning: Removing Internal Combustion Engine Light-Duty Vehicles Permanently, Quickly, and Equitably
}

\author{
Sita M. Syal, Karen Eggerman, and Margot Gerritsen
}

Stanford University

August 2021

We gratefully acknowledge the DIVE research group and our project advisors for their work to support this paper and for their input: Nora Hennessy, Nadim Saad, Greg Forbes, Rusty Klassen, Efren Carrillo, Alegria De La Cruz, Trisha Litong, Julia Varboncoeur, and Marcella Barrios. 


\section{True Decommissioning: Removing Internal Combustion Engine Light-duty Vehicles Permanently, Quickly, and Equitably}

In this paper, we introduce True Decommissioning, which we define as removing internal combustion engine (ICE) light-duty vehicles (LDVs) from the road permanently, quickly, and, equitably. Significant advancements in zero-emissions light-duty vehicles (ZE LDVs), including battery electric vehicles and plug-in electric vehicles, have made it possible to replace ICE LDVs with cleaner alternatives, opening the door to implementing True Decommissioning. In the United States, the transportation sector is mainly focused on encouraging adoption of ZE LDVs as well as banning sales of new ICE LDVs (e.g. Executive Order N-79-20 in California) and not explicitly focused on the removal of the 270 million LDVs operating on US roads today (US Bureau of Transportation Statistics, 2019). Although some programs exist that address removal, they have not succeeded in rapid vehicle removal at scale and benefits offered as part of the programs are not equitably distributed among the population. We must remove ICE LDVs from the road with careful consideration of the stakeholders who will be affected to ensure the transition to clean LDV mobility is done equitably.

Our True Decommissioning focus is on LDVs in the United States. This category includes passenger vehicles, small SUVs, and pick-up trucks. LDVs are important, if not critical, for employment and participation in society. They also constitute $60 \%$ of all US transportation-related greenhouse gas emissions and emit many harmful air pollutants (US Environmental Protection Agency, 2020). The consequences of climate change and air pollution-related health issues are felt by the entire population, but not equally so. We are particularly concerned about the disproportionate burdens from these consequences that people of color, low income, and other underrepresented and underserved communities experience (Robinson and Shine, 2018). In this paper, we will discuss pros and cons and how they might influence strategies for True Decommissioning implementation. For this discussion, we set our geographic boundary conditions as the US new and used LDV markets, with the acknowledgement that any action taken in the US will have implications on the global LDV markets. In this context, we will discuss US local, state, and federal policies.

Designing equitable policies, programs, and incentives for True Decommissioning is not a straightforward optimization problem. Solving this complex problem involves multiple stakeholders, their many interactions, and possibly contradictory or misaligned objectives. We have identified several components of the multi-objective optimization and address them in this paper. For example, if the goal of True Decommissioning is to reduce emissions, a blanket mandate to remove all ICE LDVs might be considered. However, if multiple stakeholders and their needs are not taken into account, a simple mandate could lead to unintended negative consequences for communities and society as a whole.

The subsequent sections discuss the following topics:

1) Three interlinked components we use to define True Decommissioning: permanently, quickly, and equitably. 
2) Next steps to implement True Decommissioning: engaging stakeholders, evaluating economic costs and benefits, and understanding current and future policies

3) Research questions needed to fully understand how to achieve True Decommissioning, including the questions our research group is currently working to answer

\section{Interlinked Components of True Decommissioning}

\section{Permanently}

Permanently removing ICE LDVs from the road in a way that does not penalize stakeholders who depend on them is fundamental to True Decommissioning.

Vehicle retirement in the transportation industry refers to the permanent removal of vehicles from the road at the end of its useful life. In the US, the length of a vehicle's useful life has increased due to factors including higher prices for new and used vehicles, improved vehicle quality, and particularly in the COVID-19 pandemic, decreased vehicle miles travelled (Colias, 2021; IHS Markit, 2021). ICE LDVs in an aging fleet continue to emit greenhouse gas (GHG) emissions, such as carbon dioxide $\left(\mathrm{CO}_{2}\right)$, and transportation-related air pollutants (TRAPs), such as nitrogen oxides and particulate matter, for longer than originally anticipated. IHS Markit (2021) reported the average age of LDVs in operation on US roads is 12.1 years in 2021 - a $15 \%$ increase in the last decade - and is expected to continue to grow. One study that analyzed US vehicle data found that the useful life of an ICE LDV can reach up to 30 years (Keith et al., 2019).

The Corporate Average Fuel Economy (CAFE) standards, designed to improve ICE LDV fuel efficiency, have become more stringent over time, yet only apply to new vehicles (US Department of Energy Alternative Fuel Data, 2021). With an aging fleet, we are not benefiting from the emissions reduction intended by improving CAFE standards. Studies have estimated the actual $\mathrm{CO}_{2}$ emissions emitted by passenger vehicles over their useful life are $30-50 \%$ higher than values reported from certification or laboratory tests (Fontaras et al., 2017). Smog tests aim to regulate emissions from existing vehicles and are required in some, but not all, US states. Test requirements vary widely in rigor across states. Many tests in place do not regulate the oldest population of LDVs and in the end, do not require permanently removing ICE LDVs that fail the test.

Removing ICE LDVs may also introduce unintended negative consequences to the US used LDV market and dependent stakeholders. The supply of used ICE LDVs will be drastically reduced if vehicles are permanently removed instead of extending the useful life. The resulting decreased availability may cause hardships to the communities that rely on used markets. Stakeholders in supporting industries will also be adversely affected by the disruption to the used car markets, including mechanics, dealerships, and car manufacturers. Any strategy that aims to permanently remove ICE LDVs from US roads must consider the stakeholders and markets that depend on these vehicles in conjunction with the emissions reduction potential. 


\section{Quickly}

For True Decommissioning to be effective, we must couple the permanent removal of ICE LDVs with a quicker than market rate removal.

ICE LDV removal rates have not increased significantly in the US, even with ZE LDVs increasing to nearly 1.8 million vehicles in 2020 , as depicted in Figure 1 . The annual percentage of scrapped US LDVs has remained between 4\% and 7\% since 1995 (US Bureau of Transportation Statistics, 2014). The total number of ICE LDVs has steadily increased during that time (US Bureau of Transportation Statistics, 2019). Keith et al. (2019) conducted a simulation that found even under the assumption that all new LDV sales in the US switched to ZE LDVs today, the market would still take an estimated 20 years to reduce ICE LDVs to $10 \%$ of the overall fleet. This estimate is possibly an underestimate because the authors used vehicle retirement average values and did not take into account the ever-increasing usable life discussed in the previous section.

$$
\text { - Scrappage Rate - ICE LDVs - ZE LDVs }
$$

$8.00 \%$

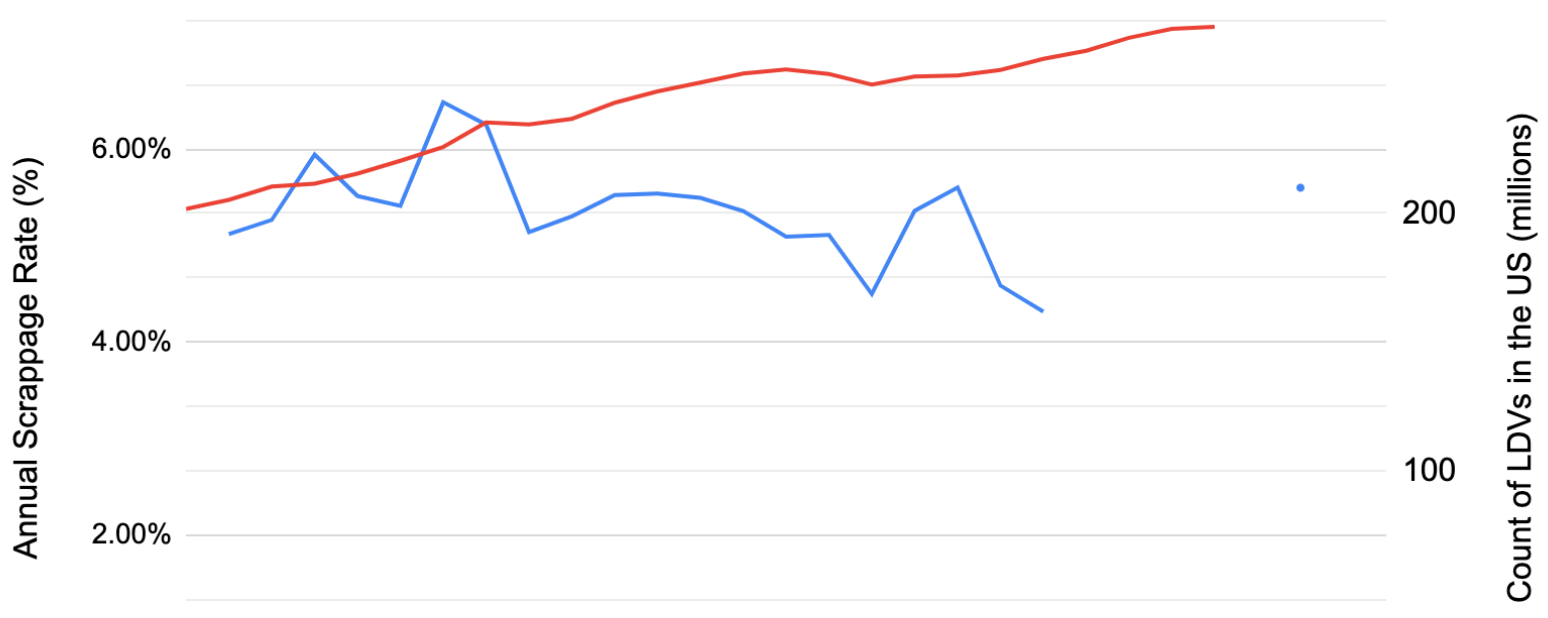

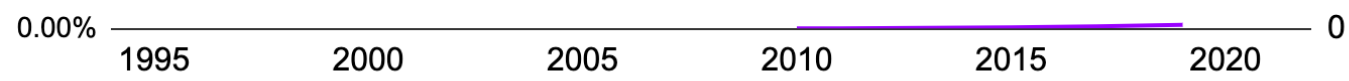

Figure 1: LDV Scrappage Rate and Number of LDVs on US roads | The number of ICE LDVs (right axis) is steadily increasing and the LDV scrappage rate (left axis) has remained fairly constant since 1995. ZE LDVs (right axis) were introduced commercially in 2010 and grew to nearly 1.8 million vehicles on US roads by 2020. Scrappage data ends in 2014 from the BTS; IHS Markit found scrappage rates in 2020 were $5.6 \%$, represented by the blue dot on the graph. (Data Sources: US Bureau of Transportation

Statistics, 2019; IHS Markit, 2021)

Leaving ICE LDV removal to market forces alone, without interventions to stimulate decommissioning, will not be quick enough to avoid global and local consequences caused by tailpipe emissions. As per the Paris Climate Agreement, we must decrease GHG emissions to 
net zero by 2050 to limit global warming to $1.5^{\circ} \mathrm{C}$ (Intergovernmental Panel on Climate Change, 2018). ICE LDVs also emit TRAPs that directly cause a significant number of deaths in the US (Thakrar et al., 2020) and other negative health effects. These effects include cardiovascular disease and non-allergy respiratory disease (Kryzanwski, 2005).

The economics of removing ICE LDVs that still have useful life pose a significant challenge to increasing removal rates. In a thriving used car market, there is little incentive to decommission a vehicle that retains some economic value. Car owners in low to middle income communities may not have the financial means to buy another car without selling their old car in the used market. Stakeholders in supporting industries, such as car repair, manufacturing, and finance, also face economic barriers to promoting the removal of ICE LDVs with useful life left. If we are serious about removing vehicles quicker than the market rate, financial incentives need to be available to a range of stakeholders.

The few government programs that incentivize ICE LDV removal are designed to encourage vehicle retirement and have not achieved rapid removal with the associated benefits. Example programs include the federal program CARS (better known as "Cash for Clunkers") (US Department of Transportation, 2009), and the California state program Clean Cars for All (California Air Resources Board, 2016). Car owners can trade in their end-of-life ICE LDV and receive a financial incentive. The amount of the incentive varies based on the program and is always much smaller than the cost of a replacement LDV. These programs offer benefits to a limited population and do not include incentives for stakeholders in supporting industries, such as mechanics and dealerships. After examining the program results, studies have shown the emissions savings from vehicle retirement programs are not as positive as originally anticipated (Dill, 2004; Lenski et al., 2010). To achieve True Decommissioning, we believe government programs must be carefully redesigned with a better understanding of the economics of rapid ICE LDV removal and the stakeholders who are intended to benefit from these programs. And, if we as a society decide to spend the money required to implement these programs, we must ensure the allocation is done in an equitable fashion.

\section{Equitably}

When it comes to mobility choices, policies, and emissions impacts, inequity is present almost everywhere. In order to achieve the goals of True Decommissioning in an equitable way, we must elevate equity to be front and center. This elevation must be done throughout the entire research and implementation process, not left to the end as an afterthought.

We have used the concept of equity throughout the paper thus far. We believe focusing on equity rather than equality is important because burdens weigh on individuals differently and barriers to accessing benefits vary. Factors such as identity, life experiences, and societal pressures can dictate the level of agency one has to improve their life. An equal distribution of resources does not give everyone the same opportunities. Equity is an important motivator for our work and we want to ensure True Decommissioning does not trade one burden for another. 
We have observed that there is no standard definition for equity in this field. Existing definitions often consider burdens and benefits, leaving agency out of the discussion. We define an equitable state for an individual as the balance between the burdens they can handle, the benefits they need for their wellbeing, and the agency to have control over their own life - all of which may differ from person to person based on their life situation and experiences. Figure 2 depicts the interlaced nature of the components needed to achieve equity.

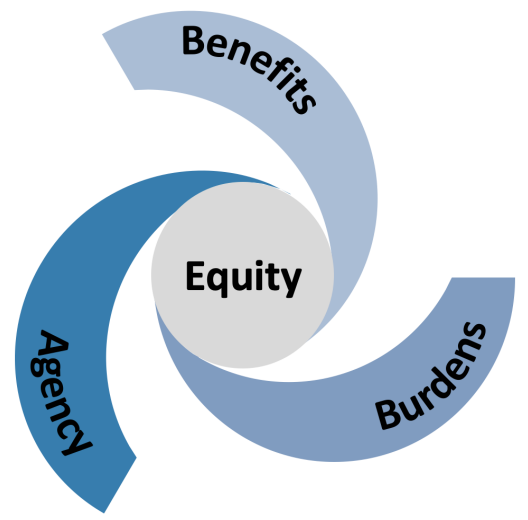

Figure 2: Components of Equity | An equitable state requires equity in burdens, benefits, and agency.

Inequities persist in the transition to clean mobility. For example, we have heard stories in interviews where individuals in low income communities carry higher burdens as a result of owning older, more polluting LDVs that are necessary for their livelihood. They cannot access financial incentives and benefits to help purchase a ZE LDV or newer ICE LDV. Furthermore, these individuals often do not have a good credit score and cannot obtain a loan with reasonable interest rates to afford another option, thus taking away agency.

To better understand equity in True Decommissioning, we discuss the following topics in greater detail:

1. Burdens due to ICE LDV emissions

2. Barriers to ICE LDV alternatives

3. Agency in transitioning to clean LDV mobility

4. Unintended consequences caused by True Decommissioning

\section{Burdens Due to ICE LDV Emissions}

The impacts of climate change, caused in part by ICE LDV-emitted GHG emissions, do not affect all communities equally. The increased risks of extreme weather and temperature, sea-level rise, and threats to biodiversity disproportionately impact poor and marginalized communities (Robinson and Shine, 2018). Many of the hardest hit communities in the US cannot participate in climate adaptation, such as moving away from vulnerable areas, and do not have the means to recover after an extreme event occurs (Morello-Frosch et al., 2009). A well-known example is the destruction and displacement caused by increased wildland fires in the Western region of the US due to warming temperatures (Abatzoglou \& Williams, 2016). 
People of color and socioeconomically insecure communities are more vulnerable to the negative effects of wildland fires (Davies et al., 2018).

On a local scale, TRAPs emitted by our society's current fleet of ICE LDVs disproportionately affect specific communities. The heavy-duty transport sector, including large shipping trucks also contribute to this emissions burden. In the US, people of color and low-income households are more likely to live near major roadways (Pinto de Moura and Reichmuth, 2019). Systemic racism and classism withholds agency from these populations to move elsewhere. These same communities are known to experience higher exposure to TRAPs (Tessum et al., 2021; Di et al., 2017), which leads to exacerbated health effects. Permanently and quickly removing ICE LDVs can help to alleviate these burdens and improve human health and wellbeing.

\section{Barriers to ICE LDV Alternatives}

We must also consider that implementing True Decommissioning could increase barriers to mobility access for those who rely on ICE LDVs. LDVs serve an important function in society by allowing people without access to public transportation or other means of transportation to participate in the workforce, education, and other activities. An estimated $45 \%$ of Americans do not have access to reliable public transit (American Public Transportation Association, 2021). Micromobility solutions, including e-bikes and scooters, are not practical for large-scale deployment in semi-urban or rural areas. For many communities, barriers exist to accessing ZE LDV alternatives to their ICE LDVs. Through our research and community engagement, we see these barriers emerge in three broad categories: 1) financial, 2) infrastructure, and 3) administrative.

Financial barriers to ZE LDVs exist in many forms (Rezvani et al., 2015). It is well known that ZE LDVs have a high upfront purchasing cost. Even with rebates or incentives, purchasing a new ZE LDV for tens of thousands of dollars is unrealistic for many. The used ZE LDV market is currently not mature enough to offer cost effective alternatives for those who cannot afford a new vehicle. These vehicles also require charging and individuals may not be able to afford the electricity costs, depending on their geographic location and utility provider. In addition to the high direct cost of ZE LDVs, systemic barriers impede access to financing mechanisms intended to support the purchase of a vehicle for many individuals. As mentioned earlier in the section, individuals who do not have a good credit score can only obtain loans with very high, unreasonable interest rates, putting a ZE LDV purchase out of reach. We have heard stories from individuals in low income communities that to find the right financing option, their credit score had to be pulled multiple times, making their already-low credit score even lower. The structure of our society's financial institutions creates barriers that prevent many people from participating in the transition to clean LDV mobility.

Charging availability is the primary infrastructure challenge to ZE LDV adoption. A lack of public charging infrastructure can discourage the purchase of ZE LDVs for many people. This lack of infrastructure is especially relevant for those who cannot access their own charger, such as renters, or those whose employers do not offer the benefit of chargers. The public charging infrastructure that does exist is not always available to all populations. One study in California 
found that public charging access in the state is lower for low income and communities of color (Hsu and Fingerman, 2021).

Administratively, current government programs intended to remove barriers to ZE LDV adoption may not be accessible to all communities. For example, one study found low income households in the metro Atlanta area were less likely to be eligible for ZE LDV federal tax credits due to factors such as tax bracket and family makeup (Liu et al., 2020). On a state level, researchers at UC Berkeley found California's Clean Vehicle Rebate Project (CVRP) has issued a larger number of ZE LDV rebates per capita to higher-income, whiter communities (Ju et al., 2020). Programs such as CVRP often use rebates, which are difficult for lower income households to take advantage of. Excessive paperwork and multiple steps to apply for incentives renders the benefit inaccessible to those who cannot afford the time or resources. Navigating the process online, comprehending the legal wording, and overcoming language barriers can make the process more difficult. Even finding out about available incentives is a barrier for many communities that programs intend to target. It is very likely that there are additional barriers that communities face in purchasing ZE LDVs that we have yet to uncover. As an example, California's Clean Cars for All program (California Air Resources Board, 2016) attempts to remove these barriers and equitably provide resources to low income communities to purchase a ZE LDV and trade in their old ICE LDV. A recent evaluation of this program has prompted California's Air Resource Board and the regional Air Quality Management Districts to re-think how the program works and who it serves. We look forward to seeing the changes and how the revised program is implemented throughout the state.

\section{Agency in Transitioning to Clean LDV Mobility}

The agency of an individual to change their distribution of burdens and benefits is deeply interwoven throughout all aspects of the transition to clean LDV mobility. Lack of agency is a crucial barrier to achieving a truly equitable state and is often overlooked. In an equitable society, for example, all individuals should have the agency to move away from areas with poor air pollution or locations sensitive to climate change effects, but many cannot. In another example, individuals without adequate health care and insurance have limited options to alleviate the hardships that come with TRAP-related health effects (i.e. disabilities, chronic diseases, lost days of work). As a third example, discussed throughout this section, individuals do not have options to improve their credit score and cannot obtain a reasonable interest rate on their car loan because of their low credit score. Systemic oppressions remove agency from individuals to improve their life and their family's life. True Decommissioning must focus on empowering individuals to have agency over their mobility choices, rather than removing agency.

\section{Unintended Consequences Caused by True Decommissioning}

The path to achieving True Decommissioning without consideration of equity can cause unintended consequences both domestically and internationally.

Regulations in the US intended to support the transition to clean mobility may engender unforeseen reactions and unknowingly affect many communities. For example, the Executive 
Order N-70-29 in California banning all new ICE vehicle sales by 2035 (California Office of the Governor, 2020) could cause people to hold onto their ICE LDVs for longer if they cannot afford or do not want to purchase a new ZE LDV. This regulation may end up supporting the continuation of the used ICE LDV market instead of supporting the transition to clean LDV mobility. More ICE LDVs on the road for longer will most likely increase the emissions burden on low-income communities, communities of color, and other disadvantaged communities.

Beyond US borders, a study conducted by the United Nations found that the US is one of the three largest exporters of used vehicles to other countries (United Nations Environment Programme, 2020). Many of these countries have less stringent emissions regulations than the US. Exporting ICE LDVs allows those vehicles to continue emitting global GHG emissions and shifts the TRAPs to other locations. The useful life of these ICE LDVs will most likely be extended as well. While the exact relationship between economic growth and car ownership is currently unclear, disrupting the supply of ICE LDVs may also have negative impacts on these countries and their growth. We must better understand the global implications of removing ICE LDVs and anticipate unintended consequences of the strategies that are implemented.

\section{Next Steps to Implement True Decommissioning}

In order to build the complex system required to achieve True Decommissioning, we must understand the individual parts of the multi-objective optimization problem and how they interact with each other. We believe the next steps fall into three main areas, which we discuss in this section.

\section{Engage Stakeholders}

Researchers and decision makers must intentionally engage stakeholders from the very beginning to understand their needs and barriers to accessing ZE LDV alternatives and decommissioning ICE LDVs. A stakeholder can be an individual or an entity that is affected by or can affect an action, event, policy, or decision (Freeman, 1984; Volger et al., 2017). The list of stakeholders include: vehicle users, community members indirectly affected by transportation systems, employees of the transportation and manufacturing industry, insurance companies, financial institutions, and federal, state, and local government agencies. We are particularly interested in elevating the voices of stakeholders in underserved communities, as discussed in the previous section.

\section{Evaluate Economics Costs and Benefits}

To make significant and rapid progress toward True Decommissioning, we must better evaluate the economic costs and benefits of removing ICE LDVs. We need to understand the economic value of the current ICE LDV fleet in the US, including outstanding useful life, loan payments, and lease payments. Analyzing used car market data can assist decision makers in understanding the link between car buyer/lessee purchasing decisions and turnover rates in order to determine how those decisions affect ZE LDV penetration. A more thorough understanding of the benefits of removing ICE LDVs is also an important consideration to True 
Decommissioning, including the averted costs of climate change and reduced health costs due to avoided emissions.

\section{Understand Current and Future Policies}

Driving rapid ICE LDV removal at such a large magnitude in the most equitable way is not possible without policies that support clean mobility for all. To make True Decommissioning a reality, we need to understand the relevant policies that are currently in place, as well as policy frameworks that can be used for future action. We also want to understand how to support communities through programs and incentives. Even if policies explicitly call out equity as a priority, this focus may not happen in practice. Governments at all levels - federal, state, and local - must be involved in designing better policies to ensure potential benefits are distributed equitably and populations are not left behind.

\section{Research Questions to Achieve True Decommissioning}

In addressing True Decommissioning, it is clear that a large number of research questions have come up, many of which are unanswered. We have provided a table of questions in the Appendix that is far from exhaustive. If you are working in this space, we invite you to reach out and let us know if you have made progress in the areas we have listed or are working on related research questions that we have not listed.

We have started to work on some of these outstanding questions that were chosen based on a combination of data availability, expertise, and criticality. The overarching goal of our research group, DIVE (Decommissioning ICE VEhicles), is to develop effective and, above all, equitable policies and incentives to decommission ICE LDVs and ensure true removal of trailing emissions from this source. We are collaborating with partners in the local government and communities in Sonoma County, California for the initial phase of our project. We aim to answer our research questions and test solutions locally with the intent that our insights will be scalable to other communities.

In summary, we have introduced True Decommissioning as the removal of ICE LDVs from the road permanently, quickly, and, equitably. We discussed the next steps to implementing True Decommissioning, including engaging stakeholders, evaluating economic costs and benefits, and understanding policies and programs. Finally, we presented a table of unanswered research questions, including those our research group is working on. There is much research to be done, and we would like to invite people to connect with us if they are working in this area. We welcome discussions on how we can achieve True Decommissioning and work together to facilitate an equitable transition to clean LDV mobility for all. 


\section{Appendix}

Table 1: Unanswered Research Questions for True Decommissioning

\begin{tabular}{|c|c|c|}
\hline Engage Stakeholders & Evaluate Economic Costs and Benefits & Understand Current and Future Policies \\
\hline $\begin{array}{l}\text { Who are the stakeholders in True } \\
\text { Decommissioning and how do they } \\
\text { interact? } \\
\text { - What are the LDV needs and constraints } \\
\text { of stakeholders? Especially interested in } \\
\text { equity, what are the needs of low-income } \\
\text { communities and communities of color? }{ }^{*} \\
\text { - What are adequate alternatives for LDVs } \\
\text { that are affordable? } \\
\text { - How to improve access to ICE LDV } \\
\text { alternatives? (marketing, advertisement, } \\
\text { infrastructure, etc.) } \\
\text { - What are the barriers to ZE LDVs? * } \\
\text { - What are the most equitable mechanisms } \\
\text { and incentives to help make ZE LDVs } \\
\text { accessible to low income communities? * } \\
\text { - Are alternatives (public transportation, } \\
\text { micromobility, etc.) actually better options? } \\
\text { In what locations? } \\
\text { Which ICE LDVs should we target first for } \\
\text { removal? What metric(s) to consider when } \\
\text { deciding on removal? This may include } \\
\text { age of car, level of use, number of miles, } \\
\text { who is the owner, and what is the primary } \\
\text { household use of the vehicle. } \\
\text { affected by decommissioning and how can } \\
\text { they best adapt? I.e. mechanics, }\end{array}$ & $\begin{array}{l}\text { What is the economic value of the current } \\
\text { ICE fleet in the US? }{ }^{+} \\
\text {What is the cost to decommission ICE } \\
\text { - How in CA? }{ }^{+} \text {In the US? In the world? } \\
\text { LDVs and putting them on the road } \\
\text { compare to leaving ICE LDVs on the } \\
\text { road? } \\
\text { - What is the cost to scrap all ICE LDVs on } \\
\text { the road? } \\
\text { What is the cost to convert a massive } \\
\text { amount of ICE LDVs to ZE LDVs? Who is } \\
\text { already working on this? } \\
\text { - How will ZE LDV financing change as } \\
\text { battery costs decrease? } \\
\text { Who owns what kind of LDV and is it } \\
\text { possible for owners of older ICE LDVs to } \\
\text { find an alternative? How should financial } \\
\text { incentives be equitably distributed to help } \\
\text { owners find an alternative to ICE LDVs? } \\
\text { - Is LDV ownership and GDP/economic } \\
\text { growth correlated? Causal? } \\
\text { Instead of "car aid" can we be sending } \\
\text { aid to build a clean transportation } \\
\text { network? Especially if we stop importing } \\
\text { used ICE LDVs? } \\
\text { circular economy affect the economics of } \\
\text { decommissioning? }\end{array}$ & $\begin{array}{l}\text { What kinds of policies and programs exist } \\
\text { that address equity in decommissioning? } \\
\text { - } \\
\text { For new policies and programs, how can } \\
\text { we measure equitable outcomes? Ensure } \\
\text { effectiveness? } \\
\text { - What types of programs to buy ZE LDVs } \\
\text { will be most effective for different groups } \\
\text { of the population (rebates, grants, tax } \\
\text { credits, carpool lane stickers, others)? }{ }^{*} \\
\text { - Who is benefiting now from LDV-related } \\
\text { policies? Who should benefit from these } \\
\text { policies? How can we measure equity? } \\
\text { What are the goals of programs that are } \\
\text { put in place and how do those goals drive } \\
\text { different outcomes (i.e. increase ZE LDVs } \\
\text { on the road, lower GHG emissions, etc.) ? } \\
\text { - } \text { W } \\
\text { What complementary policies are needed } \\
\text { to ensure ZE LDVs are being charged } \\
\text { with clean energy from the grid? } \\
\text { - How does decommissioning affect traffic } \\
\text { congestion and what kind of policies are } \\
\text { needed to transition to clean LDV } \\
\text { mobility? }{ }^{\wedge} \\
\text { if everyone drives a ZE LDV? } \\
\text { LDVs does not hinder emergency }\end{array}$ \\
\hline
\end{tabular}




\begin{tabular}{|c|c|c|}
\hline $\begin{array}{l}\text { dealerships, used car markets, } \\
\text { manufacturers, gas station owners } \\
\text { What are environmental justice } \\
\text { implications of manufacturing ZE LDV } \\
\text { parts abroad and what are the geopolitical } \\
\text { and pollution implications of increasing } \\
\text { production? }{ }^{\Delta}\end{array}$ & $\begin{array}{l}\text { - How will increasing the ZE LDV market } \\
\text { influence the market for other renewable } \\
\text { energy sources in terms of cost and } \\
\text { supply chain? } \\
\text { - How will the gas tax be replaced if the } \\
\text { fleet is electrified? }\end{array}$ & $\begin{array}{l}\text { situations (i.e. hospital trips, wildland fire } \\
\text { evacuations) } \\
\text { - How can we use policies to drive a system } \\
\text { approach to clean mobility for all - } \\
\text { cooperate between regional, state, and } \\
\text { national governments? } \\
\text { - What are the national security issues that } \\
\text { arise if we decommission ICE LDVs and } \\
\text { electrify the LDV fleet in the US? } \\
\text { What are the tradeoffs between allowing } \\
\text { used ICE LDVs to be sold in developing } \\
\text { countries vs. keeping them in-country and } \\
\text { recycling the parts? }\end{array}$ \\
\hline
\end{tabular}

* We are studying this question through stakeholder interviews in Sonoma County (conducting interviews in summer 2021).

${ }^{6}$ We are studying this question in the context of California's Clean Cars for All program.

We are studying this question by analyzing data from California's Clean Cars for All program.

${ }^{\Delta}$ We are studying this question through a literature review and in the context of California's Clean Cars for All program.

+We are studying this question for Sonoma County through data analysis of records from the DMV.

$\wedge$ We are studying this question through modeling. 


\section{References}

Abatzoglou, J. T., and Williams, A. P., 2016, "Impact of Anthropogenic Climate Change on Wildfire Across Western US Forests," PNAS, 113(42), pp. 11770-11775.

American Public Transportation Association, 2021, "Public Transportation Facts," accessed at: https://www.apta.com/news-publications/public-transportation-facts/\#: :text $=45 \% 25 \% 20$ of $\% 20$ Americans $\% 20$ have $\% 20$ no, best $\% 20$ for $\% 20$ connecting $\% 20$ with $\% 20$ communities.

California Air Resources Board, 2016, "Clean Cars 4 All," accessed at: https://ww3.arb.ca.gov/msprog/lct/vehiclescrap.htm.

California Office of the Governor, 2020, "Executive Order N-79-20," accessed at: https://www.gov.ca.gov/wp-content/uploads/2020/09/9.23.20-EO-N-79-20-Climate.pdf.

Colias, M., 2021, "Americans Are Keeping Their Cars Longer, as Vehicle Age Hits 12 Years," Wall Street Journal, accessed at: https://www.wsj.com/articles/ average-u-s-vehicle-age-hits-record-12-years-11623680640.

Davies, I. P., Haugo, R. D., Robertson, J. C., and Levin, P. S., 2018, "The Unequal Vulnerability of Communities of Color to Wildfire," PLoS ONE, 13(11), pp. E0205825.

Di, Q., Wang, Y., Zanobetti, A., Wang., Y, Koutrakis, P., Choirat, C., Dominici, F., and Schwartz, J. D., 2017, "Air Pollution and Mortality in The Medicare Population," The New England Journal of Medicine, 376(26), pp. 2513-2522.

Dill, Jennifer, 2004, "Estimating Emissions Reductions From Accelerated Vehicle Retirement Programs," Transportation Research Part D, 2(9), pp. 87-106.

Fontaras, G., Zacharof, N-G., and Ciuffo, B., 2017, "Fuel Consumption and $\mathrm{CO}_{2}$ emissions from Passenger Cars in Europe - Laboratory Versus Real-World Emissions," Progress in Energy and Combustion Science, 60, pp. 97-131.

Freeman, R. E., 1984, Strategic Management: A Stakeholder Approach, Pitman Publishing, London.

Hsu, C-W., and Fingerman, K., 2021, "Public Electric Vehicle Charger Access Disparities Across Race and Income in California," Transport Policy, 100, pp. 59-67.

IHS Markit, 2021, "Average Age of Cars and Light Trucks in the U.S. Rises to 12.1 years, Accelerated by COVID-19, According to IHS Markit," accessed at: https://news.ihsmarkit.com/prviewer/release_only/id/4759502/.

Intergovernmental Panel on Climate Change, 2018, "Summary for Policymakers," Global Warming of $1.5^{\circ} \mathrm{C}$. An IPCC Special Report on the impacts of global warming of $1.5^{\circ} \mathrm{C}$ above pre-industrial levels and related global greenhouse gas emission pathways, in the context of strengthening the global response to the threat of climate change, sustainable development, and efforts to eradicate poverty, Eds. Masson-Delmotte, V., P. Zhai, H.-O. Pörtner, D. Roberts, J. Skea, P.R. Shukla, A. Pirani, W. Moufouma-Okia, C. Péan, R. Pidcock, S. Connors, J.B.R. Matthews, Y. Chen, X. Zhou, M.I. Gomis, E. Lonnoy, T. Maycock, M. Tignor, and T. Waterfield, World Meteorological Organization, Geneva, Switzerland. 
Ju, Y., Cushing, L.J., and Morello-Frosch, R., 2020, "An Equity Analysis of Clean Vehicle Rebate Programs in California," Climatic Change, 162, pp. 2087-2105.

Keith, D. R., Houston, S., and Naumov, S., 2019, "Vehicle Fleet Turnover and the Future of Fuel Economy," Environmental Research Letters, 14, pp. 021001.

Krzyzanwski, M., 2005, "Health Effects of Transport-Related Air Pollution: Summary for Policy-Makers," World Health Organization, ISBN 92-890-1375-3.

Lenski, S. M., Keoleian, G. A., and Bolon, K. M., 2010, "The Impact of 'Cash for Clunkers' on Greenhouse Gas Emissions: A Life Cycle Perspective," Environmental Research Letters, 5(4)044003, pp. 1-8.

Liu, H., Guensler, R., and Rodgers, M. O., 2020, "Equity Assessment of Plug-In Electric Vehicle Purchase Incentives with a Focus on Atlanta, Georgia," Center for Transportation, Equity, Decisions, and Dollars.

Morello-Frosch, R., Pastor, M., Sadd, J., and Shonkoff, S. B., 2009, "The Climate Gap: Inequalities and How Climate Change Hurts Americans \& How to Close the Gap." Program for Environmental and Regional Equity, accessed at: https://dornsife.usc.edu/pere/climategap/.

Pinto de Moura, M. C., and Reichmuth, D., 2019, "Inequitable Exposure to Air Pollution from Vehicles in the Northeast and Mid-Atlantic," Union of Concerned Scientists, accessed at: https://www.ucsusa.org/resources/inequitable-exposure-air- pollution-vehicles.

Rezvani, Z., Jansson, J., and Bodin, J., 2015, "Advances in Consumer Electric Vehicle Adoption Research: A Review and Research Agenda," Transportation Research Part D, 34, pp. $122-136$.

Robinson M., and Shine, T., 2018, "Achieving a Climate Justice Pathway to $1.5^{\circ} \mathrm{C}$," Nature Climate Change, 8, pp. 564-569.

Sonoma County Office of Equity, "Racial Equity and Social Justice", accessed at: https://sonomacounty.ca.gov/Board-of-Supervisors/Strategic-Plan/Racial-Equity-and-Soc ial-Justice/.

Tessum, C. W., Paolella, D. A., Chambliss, S. E., Apte, J. S., Hill, J. D., and Marshall, J. D., 2021, "PM 2.5 Polluters Disproportionately and Systemically affect People of Color in the United States," Science Advances, 7(18), pp. eabf4491.

Thakrar, S. K., Balasubramanian, S., Adams, P. J., Azevedo, I. M. L., Muller, N Z., Pandis, S. N., Polasky, S., Pope, C. A., Robinson, A. L., Apte, J. S., Tessum, C. W., Marshall, J. D., and Hill, J. D., 2020, "Reducing Mortality from Air Pollution in the United States by Targeting Specific Emission Sources," Environmental Science \& Technology Letters, 7(9), pp. 639-645.

United Nations Environment Programme, 2020 "Used Vehicles and the Environment, A Global Overview of Used Light Duty Vehicles: Flow, Scale and Regulation," ISBN 978-92-807-3804-9.

US Bureau of Transportation Statistics, 2014, "Motor Vehicles Scrapped," accessed at: https://www.bts.gov/content/motor-vehicles-scrapped. 
US Bureau of Transportation Statistics, 2019, "Motor Vehicle Fuel Consumption and Travel," accessed at https://www.bts.gov/content/motor-vehicle-fuel-consumption-and-travel.

US Department of Energy Alternative Fuels Data, 2021, "Vehicle Fuel Efficiency (CAFE) Requirements by Year," accessed at https://afdc.energy.gov/data/10562.

US Department of Transportation, 2009, "CARS: Car Allowance Rebate System," accessed at https://web.archive.org/web/20091225230439/http://www.cars.gov/.

US Environmental Protection Agency, 2020, "Fast Facts: U.S. Transportation Sector Greenhouse Gas Emissions 1990-2018." Office of Transportation and Air Quality, EP-420-F-20-037.

Volger, D., Macey, S., and Sigouin, A. 2017, "Stakeholder Analysis in Environmental Conservation Planning," Lessons in Conservation, 7, pp. 5-16. 